\title{
Academic Inbreeding: A Risk or Benefit for Universities?
}

\author{
Aydın Balyer ${ }^{1} \&$ Mehmet Emin Bakay ${ }^{2}$ \\ ${ }^{1}$ Yıldız Technical University, Faculty of Education, Educational Sciences, İstanbul Turkey \\ ${ }^{2}$ Izmir Katip Çelebi University, Faculty of Economics and Administrative Sciences, İzmir, Turkey \\ Correspondence: Mehmet Emin Bakay, Izmir Katip Çelebi University, Faculty of Economixs and Administrative \\ Sciences, İzmir, Turkey.
}

Received: November 30, 2021

Accepted: January 8, 2022

Online Published: January 17, 2022

doi:10.5539/jel.v11n1p147

URL: https://doi.org/10.5539/jel.v11n1p147

\begin{abstract}
Academic inbreeding is a recruitment practice for universities of hiring their own graduates as future academicians. Despite its benefits, it may have damaging effects on the academy. From this point of view, this qualitative research investigated whether academic inbreeding brings benefits to universities or poses risks. It was also purposed to determine how academicians define academic inbreeding and experience it in their daily practices. To this end, twenty academicians were interviewed, and the data were analyzed with content analysis technique. Results revealed that while few academicians underlined its benefits, most academicians manifested its risks and negative experiences. Thus, it is recommended that mobility among academic staff should be encouraged.
\end{abstract}

Keywords: academicians, academic inbreeding, higher education, management, universities

\section{Introduction}

\subsection{Introduce the Problem}

As pioneer institutions, universities are expected to play crucial roles in social and economic development of a country in the competitive world of work. These expectations create pressure on their daily practices. In order for these institutions to meet these expectations, employing the most talented and qualified scholars and researchers has become more important than ever. For universities, employment practices specifically include recruitment, selection, and hiring of academic staff. Universities employ academic staff in different ways. In this process, while some universities prefer to employ the most talented academicians from both inside and outside the university, others have a tradition of employing their own graduates as academicians, which is called as the practice of academic inbreeding. Therefore, the main objective of this paper is to analyze the benefits and risks of academic inbreeding as an employment practice in higher education institutions. In addition, it is aimed at analyzing how academicians define academic inbreeding and experience it at universities. As there are few descriptive studies on academic inbreeding in Turkey higher education context, this research is considered to shed a light in the higher education administration field in Turkey. Moreover, by understanding academic inbreeding phenomenon at universities, this study may help academic life to improve.

\section{Theoretical Background}

\subsection{Academic Inbreeding}

According to Cambridge English Dictionary (2019) the term inbreeding is defined as a situation in which plants, animals or people are produced by breeding closely related members of the same family. Regarding academia, Gorelova and Lovakov (2016) assert that it is a practice of a university hiring its own graduates to be professors there. Also known as institutional inbreeding, universities hire their own graduates as faculty members directly after their doctoral graduation in a recruitment practice (Cruz-Castro \& Sanz-Menéndez, 2010; Horta, Sato, \& Yonezawa, 2011). Blau (1994) underlines that these faculty members possess at least one degree from the academic institution, which is employing them; most commonly this is their highest degree.

Academic inbreeding is as old as the modern university and used to be a common practice in the 19th and 20th centuries. Nowadays, it has been intensively implemented in Japan, Australia, Mexico, Argentina, China, Russia, Slovenia, Spain, South Africa, South Korea, and the United States, Portugal, Ukraine and Turkey (Altbach, Yudkevich, \& Rumbley, 2015; Horta \& Yudkevich, 2015; Pan, 1993; Padilla, 2008). Although it has been 
widely implemented in many countries, there are also discussions whether this employment practice brings benefits to universities or poses risks on academic life.

\subsection{Benefits and Risks of Academic Inbreeding}

There are arguments in favor of and against academic inbreeding. Regarding its benefits, it is indicated that academic inbreeding has positive outcomes in some cases. One point of view in favor of academic inbreeding is that it stands out as an attractive practice, especially in well-established and prestigious universities. These universities probably think that the most qualified and talented researchers are the ones educated by themselves, and they may not want to lose these graduates to survive their current prestige (Altbach, Yudkevich, \& Rumbley, 2015; Horta, Sato, \& Yonezawa, 2011; Morichika \& Shibayama, 2015; Pan, 1993). Indeed, researches show that most prestigious universities tend to employ their own students and close their doors to graduates of other universities (Massengale \& Sage, 1982; Tavares, Cardoso, Carvalho, Sousa, \& Santiago, 2015). In addition, they may consider that their own graduates are the ones who can best adapt to their faculty culture, as they are familiar with the culture and seniors they studied with (Padilla, 2008; Pan, 1993). Moreover, academic inbreeding tendencies of old universities can also guide their employment policies as being role models to newly established or developing universities. While well-established universities apply academic inbreeding to protect their own culture, newer universities may see it as a means of creating their own traditions and culture quickly (Horta, 2013; Horta, Sato, \& Yonezawa, 2011). Furthermore, employing graduates of other universities as faculty members may bring different methods and new forms of research and philosophy to a faculty (Horta, Veloso, \& Grediaga, 2010). This may also increase the capacity of a university to develop creative ideas that would open up new and original research. Hence, according to Crişan (2019) the current university educational model implies a dynamic and permanent adaptation to the training and information requirements of the individual and of the society, together with the increased emphasis on university management.

Another reason for academic inbreeding is to be effective in terms of time, energy and finance. Although a higher education institution aspires to employ the best possible candidate, it has to do so within the framework of certain budget and legal constraints. Additionally, the geographical features of universities, or the obstacles may limit the number of potential candidates for universities. Thus, financially and geographically disadvantaged universities may choose to employ their own graduates as a suitable option (Pan, 1993). In some disciplines and regions, language requirements contribute substantially to academic inbreeding (Seeber \& Mampaey, 2021).

Apart from that, the university's short-term recruitment process of its graduates shortens the process of seeking candidates, reduces various costs, and removes the risk of election of a candidate who may be a less well-known and false choice from the outside.

On the other hand, the general opinion is that academic inbreeding has negative consequences, and poses many risks on academia. According to Tavares, Sin and Lanca (2019) academic inbreeding is detrimental for the recognition and the impact of research. In this sense, according to Morichika and Shibayama (2015) it may blunt scientific creativity, lower scientific production, diminish knowledge sharing, and reduce the mobility of faculty members. It is supported by many empirical researches that candidates who are later employed as faculty members at a university in which they studied have less scientific production (Banks, 2006; Cruz-Castro \& Sanz-Menéndez, 2010; Hargens \& Farr, 1973; Horta, Veloso, \& Grediaga, 2013; İnanç \& Tuncer, 2011; Morichika \& Shibayama, 2015; Yudkevich, 2015; Horta, Meoli, \& Santos, 2021). Hence, Mishra and Smyth (2012) and Shapira, Rogers and Senker (2009) emphasizes that the mobility of faculty members between institutions or countries improves creativity in terms of research. Another negative outcome is that these scholars are usually "limited to the confines of a single institution" (Blanke, Hyle, \& Spring, 2000). Academic inbreeding, therefore, can lead the faculty to maintain their own research and teaching culture without allowing diversity. According to Horta, Meoli and Santos (2021) homegrown academics research agendas are not designed with the potential to lead to scientific discovery (and research breakthroughs, which involves a greater risk-taking attitude) as the ones of mobile academics. The research agendas of homegrown academics are also less ambitious.

A further risk is that by implementing such an employment policy, new academic members can academically become replicas of senior lecturers who had educated them. In this case, academic freedom considered as a sub-component of a university autonomy and a pre-condition of academic production, cannot be fully practiced (Albatch, 2001; Metzger, 1987; Poch, 1993; UNESCO, 2008). As a result, it may bring risks such as potential violations and restrictions, and leave faculty members vulnerable to restrictions. Moreover, academic inbreeding is closely related to the rigid working conditions resulting from the absence of a real academic labor market, and can be used as a tool by universities to direct and supervise academic labor markets (Eels \& Cleveland, 1935a, 1935b; Musselin, 2004). 
What is more, academic inbreeding practices may limit faculty members, and cause them to stay in a certain environment for a long time. It can also restrict having possible faculty experiences in different environments by forcing them to work in the same university throughout their careers and prevent investment in external qualifications, activities and productions (Altbach, Yudkevich, \& Rumbley, 2015). The research done in Spanish academia (de la Torre, Perez-Esparrels, \& Romero-Madrid, 2021) indicates that university systems with a high level of academic inbreeding tend to be closed to attracting (inter)national talent, while instead prioritizing retention of the human factor in the institution and the stabilization and continuity of internal bureaucratic dynamics.

Macfarlane and Jefferson (2021) emphasize another negative effect of academic inbreeding which is guild power. According to researchers the biggest challenge is for institutions, and indeed many individual academics, to accept that guild-route privilege not only exists but represents a form of bias and discrimination at the heart of academic life which has deleterious consequences.

Another major risk of academic inbreeding lies in the relation of new graduates who attend as an academic staff and become a senior lecturer there. Although insider faculty members are promoted to become seniors at universities they graduated from, it is possible to observe a hierarchical relationship between them (Altbach, Yudkevich, \& Rumbley, 2015; Burris, 2004; Hagstrom, 1971). Young academicians may feel obliged to obey what their seniors or advisors would say.

According to a recent research done in Russia (Alipova \& Lovakov, 2018) there is no significant effect of academic inbreeding on publication productivity: no substantial and robust differences in publication activity between inbreds and non-inbreds have been found.

As can be seen, both positive and negative outcomes of academic inbreeding have been widely discussed for universities. Regarding the Turkish higher education system, İnanç and Tuncer (2011) claims that academic inbreeding is one of the dominant employment practices for academic staff with ratios in excess of $50 \%$ and it is a question of whether it brings benefits or poses risks to academia in Turkey. In Turkey, the Council of Higher Education (Resmi Gazete, 2008) introduced a regulation put into effect to apply central examination for the appointment of teaching staff (including research assistants) and tied the selection processes to objective criteria. This change took an important step towards preventing academic inbreeding. On the other hand, in recent years, an important regulation has been made to prevent nepotism by preventing the special conditions for the individuals in academic job advertisements for academic promotions. But, still the inbreeding exist at the most of universities. Machacek, Srholec, Ferreira and Costas (2021) emphasized that the institutions in Central, Eastern and Southern Europe have the highest share of insiders, whereas institutions in Northern America and Western and Northern Europe have a higher share of foreign outsiders. Foreign outsiders are most common in small and wealthy countries.

Therefore, this qualitative research aims to analyze whether academic inbreeding brings benefits to universities or poses risks to them in Turkey context. To this end, the following questions are being researched: How do academicians define academic inbreeding? How do they experience academic inbreeding? Does academic inbreeding bring benefits or pose risks to universities?

\section{Methodology}

\subsection{Research Design}

The research employed a phenomenological research design. Phenomenological researches are conducted to find out how a concept or a phenomenon is experienced and understood by individuals (Creswell, 2007). These kinds of research are also used to gain in-depth knowledge in a study (Denzin \& Lincoln, 2005; Marshall \& Rossman, 2006). Phenomenological approaches suggest that participants should be regarded as individuals to create their own meanings in the social environment in which they live, the relations they have established, and they are re-creators of their social worlds with their own subjectivity (Balc1, 2015; Kümbetoğlu, 2005; Punch, 2005).

\subsection{Study Group}

The participants of this research were twenty faculty members chosen with purposive sampling technique. This technique is more of a research purpose than a methodological requirement and allows the researchers to select appropriate participants for the purpose of the research (Creswell, 2007; Marvasti, 2004). Qualitative researchers use this technique, because they do not work in large groups and do not intend to make generalizations. It enables them to choose rich situations for information on extensive studies and important issues (Creswell, 2007; Patton, 2002). In order to maximize their variability, a study group of 5 to 25 people for phenomenological researches is sufficient to conduct the study (Creswell, 2007; Maxwell, 1996). In addition, equal gender and 
academic titles are taken into consideration.

Table 1. The participants' demographics

\begin{tabular}{|c|c|c|c|c|c|c|c|}
\hline Gender & & Experience & & Work Field & & Academic Title & \\
\hline Male & 10 & $1-5$ years & - & Natural Science & 11 & $\begin{array}{l}\text { Assistant } \\
\text { Professor }\end{array}$ & 7 \\
\hline \multirow[t]{5}{*}{ Female } & 10 & $6-10$ years & 2 & Social Sciences & 9 & Associate Professor & 7 \\
\hline & & $11-15$ years & 8 & & & Professor & 6 \\
\hline & & $16-20$ years & 4 & & & & \\
\hline & & $21-25$ years & 4 & & & & \\
\hline & & 26 years and above & 2 & & & & \\
\hline Total & 20 & & 20 & & 20 & & 20 \\
\hline
\end{tabular}

As seen in Table 1 above, 7 participants were assistant professors, 7 of them were associate professors and 6 of them were professors. As for gender, both genders were equally presented. While 10 were male, 10 were female. Regarding their field of expertise, while 9 academics were from social sciences field, 11 were from natural sciences department. Regarding their experience, while most of them have more than 10 years of experience, only 2 have between $6-10$ years of experience.

\subsection{Data Collection and Analysis}

In this research, open-ended data were collected with qualitative interview method. This method is usually known as a semi-structured interview (Bailey, 1994; DeMarrais, 2004; Kerkhof, 2006; Kümbetoğlu, 2005). By using this method, the participants explain their ideas freely on a specific topic. In this respect, first of all, the researchers sent an e-mail to a group of academicians from different universities by explaining the purpose of the study and then asked if they were volunteer to participate in the research or not. As a result, twenty academicians accepted to participate voluntarily in the research. Secondly, an interview was planned on an agreed-upon day with volunteer participants, and they were visited on that date. The interviews were both recorded and written down with their permission and each took approximately 30-40 minutes. In this research, the participants gave their consent that the data collected from them would be kept in secret and would not be shared with anyone else or an institution. The participants were assured that their identities would be confidential, and both their names and the names of their institution would not be mentioned in any part of the study. In the data analysis process, the content analysis technique was used. This technique usually aims to analyze similar data on a topic and makes comments on it (Mayring, 2000). For this process, firstly, the data were organized. In this context, the researchers revisited each interview and listened to each recorded audiotape transcripts in order to ensure the accuracy of the data gathered. Each participant's interview transcript was later analyzed according to the data analysis procedures described by Bogdan and Biklen (2007), which involves development of coding categories, mechanical sorting of data, and analysis of data within each coding category. In this context, each academician's interview was coded separately according to his or her views on academic inbreeding. Through this research, emerging themes and repeated themes were grouped into coding categories in three steps namely, category definition, exemplification, and codification regulation. In this manner, firstly, answers to each question were categorized into meaningful categories, named, and then coded. Secondly, the conceptualized statements were collected. Thirdly, all efforts were made to avoid repetition. Finally, defined results were explained and related to each other. It was also intended to establish a cause-effect relationship among the existing parts. The participants' opinions were coded as A1, A2, A3, and A4...

In the data organization and analysis process, the constant comparative approach was used. This process resulted in the saturation of categories and the emergence of the theory. Here, theory may emerge through continual analysis and doubling back for more data collection and coding (Bogdan \& Biklen, 2007; Glaser, 1992). By applying this method, each set of gathered data were re-visited regarding key issues, recurrent events, or activities. Each participant's data were re-analyzed several times to confirm and contradict statements until the data were organized into satisfactory categories and sub-codes to address the research question.

\subsection{Trustworthiness and Rigor}

In order to provide trustworthiness and rigor, some precautions were taken. First of all, the interviewer played the role of facilitator and listener. Here the researchers just asked questions and recorded the answers without leading the participants. In addition, the questions were revised by four field experts in order to ensure content validity. After analyzing the experts' feedback, the final forms of the questions were developed. Moreover, the 
participants were assured with the confidentiality of the research to obtain in-depth answers without any hesitation. The interview places were chosen especially out of the universities to abstain from influencing some hierarchical power relations. In order to provide the validity and reliability the following precautions were taken:

While preparing the interview form, the related literature was re-examined to build a contextual frame to enhance the internal validity. What is more, the academicians were able to express their thoughts freely and sincerely as their identities were kept in confidential.

Not to mention that, research process was explained in detail in order to enhance external validity. In this process, the research design, participant, data collection and analysis processes were described in detail. Also the raw data and coded data were saved by the researchers for other researchers' further research demands.

The data were all transcribed as they were without any interpretation to provide internal reliability. The coded data were compared with that of the researchers and the consistency was calculated as $88 \%$ (Miles \& Huberman, 1994).

\subsection{Limitations}

This research has several limitations regarding the transferability of the results to the population. Firstly, the sample of participants was volunteer academicians. For this reason, they are not necessarily representatives of other academicians within other institutions. Therefore, the results obtained here are limited to this study group of academicians and while inferring the results to the population, more caution should be exercised. Secondly, the researchers were the main instruments of data analysis. The analyses and comments are the products of the researcher's interpretation of it. A different researcher may reach different features of importance within the same data sets (Bogdan \& Biklen, 2007; Creswell, 2002). Finally, although the researchers purposed to provide equal representation, it was impossible to provide a fully equal presentation of experience.

\section{Results}

This research is carried out to determine whether academic inbreeding brings benefits to universities or poses risks on them. A number of results are obtained, and in this part, these results are presented.

\subsection{The Definition of Academic Inbreeding}

In this part, academicians' views on the definition of academic inbreeding were presented.

Table 2. The definition of academic inbreeding

\begin{tabular}{lll}
\hline Themes & Codes & $\mathrm{f}$ \\
\hline Definition of Academic Inbreeding & Employing their own graduates & 10 \\
& Selection process based on personal relationships & 8 \\
& Retention of a trainee as staff after graduation & 7 \\
& Becoming academically replicas of senior lecturers & 12 \\
\hline
\end{tabular}

Note. *A participant participated in more than one view.

Although academic inbreeding has been widely practiced as a form of employment in many countries, there are still different types of definition. In this regard, an academician defined academic breeding as "...employing a university's own graduate as a faculty member. It means that you get your post graduate degree from a university and start working there as an academician." An associate professor described it as, "...a kind of nepotism, which neglects competency." Another faculty member expressed, "Hiring former students without considering their competency." A professor underlined, "...spending the entire academic life at one university." An assistant professor stated, "Employing trainees as academic staffs after their graduation to work in a very familiar environment without experiencing other academic environments, culture and meeting different scholars" An academic staff defined, "... becoming academically replicas of their senior lecturers." Considering all definitions made by participants, academic inbreeding is broadly defined as a practice for universities of employing their own graduates as academicians. In this employment practice, academicians most probably spend their whole academic life at the same institution without experiencing a different academic environment and meeting different scholars. As İnanç and Tuncer (2011) claims that the tradition of hiring their own graduates is a quite common practice at universities in Turkey.

\subsection{Academic Inbreeding Experiences}

In this part, academicians' views on their academic inbreeding experiences are analyzed. 
The findings are presented below.

Table 3. Academic inbreeding experiences

\begin{tabular}{lll}
\hline Theme & Codes & f \\
\hline & Interventions & 10 \\
& Good relationships with their advisors & 6 \\
Academic & Having support from their advisors & 5 \\
Inbreeding & Good teamwork & 4 \\
Experiences & Easy adaptation process & 3 \\
\hline
\end{tabular}

Note. *A participant participated in more than one view.

When academicians' academic inbreeding experiences are analyzed, it can be said that most academicians experience interventions in their academic relationships with their advisors. A participant stated, "Having such experience was bad for me. For instance, once my advisor invited me to a master's thesis jury. I made very careful criticisms, but my advisor was very angry with me. Furthermore, I could not feel like a teacher when I was working with my advisor. I could finally become a real lecturer when my advisor got retired". An assistant professor said, "When I intended to design a course, my advisor checked the course content, and asked me to change it. Unfortunately, I changed it, because I thought it would be a problem for my promotion." Another faculty member said, "My supervisor intervened many things. He forced me to study in a group I did not want to take part, and it was impossible to resist, I had to obey it."

However, some academicians noted having good relations with their advisors and being supported by their senior professors. It was also discovered that having such an experience helped them adapt easily to their institutions as they are familiar with the institutional culture there. An assistant professor underlined, "My advisor never quitted helping me and he always motivated me to do good things." Another faculty member stressed, "It's like being at home to work at the same department. After I started working here, my relationship with senior professors continued as it used to be a student of them. In fact, it was a good experience for me." A professor said, "Regarding the adaptation process, outsiders have a lot of difficulty. For example, they avoid teamwork, and their commitment is low." Another faculty member emphasized, "It was a good experience to work at the same department, because I was familiar with everybody here." An academician expressed, "This was a good experience and having such experience made things easier for me and helped me to develop my sense of belonging to my faculty."

The analyses of interviews demonstrate that faculty members' academic inbreeding experiences are quite different from each other. In this context, findings show that most faculty members feel interventions. They underline the fact that their seniors want to lead them to pursue studies in their own interest of research. Although they consider working with their advisors as sometimes useful, they sometimes face limitations in many areas, which is problematic with the use of academic freedom. It seems that they do not feel fully independent. On the other hand, some faculty members emphasize that it is a good experience for them. They argue that they have good relations with their advisors during their postgraduate studies, and they feel as if they are at their home. This experience helps them to develop a sense of belonging to their institution as well.

\subsection{Risks or Benefits of Academic Inbreeding}

In this part, academicians' views of the risks or benefits of academic inbreeding are analyzed. The findings are presented below.

Table 4. The risks or benefits of academic inbreeding

\begin{tabular}{lll}
\hline Theme & Codes & f \\
\hline Risks or benefits of academic inbreeding & Poses a lot of risks & 13 \\
& Brings a lot of benefits & 76 \\
& Poses/bring neither risks nor benefits & - \\
\hline
\end{tabular}

Note. *A participant participated in more than one view.

Regarding academicians' views on the benefits or risks of academic inbreeding, most academicians consider that academic inbreeding poses a lot of risks for the future of universities. They evaluate that as a result of academic inbreeding practice, most academic staff become replicas of their seniors after some time, and there can be no 
room left for diversity. Hereof, an academic claimed, "Academia needs different points of views and diversity. It leads to free thought and creativity. Those who come from other universities may have a tendency of pursuing similar fields of studies with their seniors." An associate professor underlined, "When I first came to this university, there was an academic hegemony. Young academicians could not pursue their research independently. They usually asked for their seniors' approval. Naturally, it poses risks for academia". Another faculty member claimed, "When an academician spends all his/her academic life at the same institution, they cannot experience different cultures and meet different academicians from other cultures. Therefore, they cannot develop a different point of view." On the other hand, few academicians defended its benefits. Here, an academic claimed, "It is beneficial for a university. When you work for the same university from which you graduate, you know the academic culture and your seniors' expectations there. Personally, this makes a lot of things easier both for academic staff and the university. For example, personally, if I did not know the culture, I would have faced a lot of problems to adapt to the culture. Also, employing their own graduates is easy as it takes short time and less costly."

An associate professor underlined, "Indeed, other university graduates cause a lot of problems as they carry their graduated university's tradition to here. Therefore, academic inbreeding practice becomes an advantage for a university." A professor emphasized, "When we employ new academics outside from the university, we face many problems. They do not respect rules, and object to most of the decisions." Regarding evaluations of participants' views on the benefits and risks of academic inbreeding, it can be inferred that academic inbreeding practice is commonly considered as risky. The participants contemplate that this employment practice pose more risks than benefits in academic life for some reasons. First of all, as a result of such an employment policy, academic staff may become similar lecturers in the long term. In such an environment, new faculty members can be under the influence of their seniors, and they may have a tendency to adopt their seniors' habits and research practices. Secondly, it is also implied that as a result of employing their own graduates, academic staff cannot experience different academic cultures and meet different scholars educated from different universities. Also, it becomes almost impossible for candidates to get a position at a university from other universities. Thirdly, in this employment practice, academic competency can be ignored, which may pose risks for academia as well. Finally, academicians from diverse background cannot find a chance to bring new points of views from their own experiences.

However, some other faculty members underline benefits of academic inbreeding. Those who underlines the benefits evaluate that when you graduate from the same university for which you work, you become familiar with the academic culture and your seniors' expectations. And this reduces the problems of adaptation. Moreover, academicians from other universities are believed to cause some problems since they carry the traditions of the university they graduate from.

\section{Conclusion, Discussions, and Implications}

This research is carried out to determine whether academic inbreeding poses risks or brings benefits to Turkish universities. It is also aimed to find out how academicians define academic inbreeding and how they experience it. To this end, some results are obtained. Firstly, our sample population of academicians defines academic inbreeding as employing trainees as academic staff after their graduation to work in a very familiar environment

without experiencing other academic environments, culture and meeting different scholars. As a result of such an employment policy, first, they become reciprocal assimilation of senior academic staff. In other words, they become replicas of their senior lecturers. In such a culture, it is claimed that new faculty members can be under the influence of former supervisors, and they may continue their seniors' habits and research practices. It is considered that it may affect academic freedom in a negative way. Especially, young academicians may have some hesitations to generate knowledge because of probable pressures that can come from their seniors. In general, academicians in our sample believe that academic inbreeding has recently become a common practice, and it becomes an important risk for Turkish universities. This result was supported by the research conducted by İnanç and Tuncer (2011). In their study, they discover that academic inbreeding is a very common practice in Turkey with ratios in excess of $50 \%$. This kind of employment practice does not also give chance to diversity among candidates from other institutions or backgrounds. In fact, diversity and mobility among academic staff can provide different points of views and as a result of it, students can benefit from it. This can also help exchange information among academic staff and establish cooperation with each other.

According to another result of our research, participants manifest their academic inbreeding experiences differently. Within this context, while most academicians report their experiences as positive, other faculty members emphasize negative experiences. Academicians noting positive experiences claim that they have good 
relations with their seniors during their post graduate studies, and they feel as if they are at their homes. Their experiences also help them to establish good interactions with their seniors and develop a sense of belonging to their university. Thanks to this employment practice, they feel comfortable within the institution and they adapt the culture there easily. As they are already familiar with people and culture there, it makes things easier both for them and the institution they work for. Similar results were also obtained by Padilla (2008). He argues that organizational commitment is much higher at universities where academic inbreeding is high. Also, Laufer (2020) indicates that the presence of academic inbreeding within a higher education system increases the significance of social ties. According to Göktürk and Yıldırım-Tastı (2020) although academic inbreeding policies and practices seem universal and functional, there are still unaddressed issues on the contested character of the institutional and research culture it produces.

However, faculty members who emphasize negative experiences underline that their seniors want to lead them to pursue their own research studies, which is an intervention to academic freedom. In this manner, they express that they are being subjected to limitations in many areas. Their academic freedom is limited, and most of the time their seniors want them to get their approval in many new initiations. Eventually, young academicians cannot feel fully independent, and it may affect their scientific knowledge production accordingly. This result is consistent with the results of other researches. In this context, İnanç and Tuncer (2011) and Eisenberg and Wells (2000) claim that academic inbreeding adversely affects scientific productivity and effectiveness. Those who come from other universities have $35 \%$ higher h-index ratios comparing to those who are employed as academic inbreeding. This shows that ignoring academic competency can affect the quality of scientific knowledge production negatively, and it may pose many risks for academia in the long run. In their study, Inanç and Tuncer (2011) and Altbach, Yudkevich and Rumbley (2015) disclose that it appears to be favoritism for a university to hire their own doctoral graduates as new faculty members. In fact, favoritism should not be tolerated at universities because it can be a serious risk for the future of universities. One of the basic expectations from academia is the production of qualified scientific knowledge. For this purpose, it is considered that universities should employ the most qualified and talented academic staff. Hence, Mishra and Smyth (2012) and Shapira, Rogers and Senker (2009) emphasize that the mobility of the faculty members between institutions or countries has improved creativity in terms of research. Similarly, Tavares, Lança and Amaral (2015), İnanç and Tuncer (2011), Kozikoğlu (2016) and Horta et al. (2010) investigate relationship between academic inbreeding and scientific knowledge production and they conclude that there are negative effects of academic inbreeding in terms of scientific efficacy. In addition, Altbach, Yudkevich and Rumbley (2015) and Yudkevich (2015) discover that academic inbreeding may cause localization with a small contribution to total scientific production even if there are too many publications. What is more, Harto and Veloso (2010) mention that those who are educated through academic inbreeding are not very aware of the development of scientific knowledge. Last but not least, Morichika and Shibayama (2015) criticize academic inbreeding claiming that it reduces production and sharing of experience, because it does interfere with intellectual interaction.

A final result of our research exposes that few academicians accept academic inbreeding as a beneficial form of employment practice. In this regard, first of all, they assert that insider faculty members are familiar with the current institutional culture, and they feel more comfortable at the university they graduate from. In this sense, it is stated that although teaching staff coming from other universities can provide diversity to the departments, they have also difficulty regarding adaptation process. Balyer and Ömür (2018) present similar results. In their study, they discover that lecturers find academic inbreeding useful, because it makes them feel familiar with organizational culture. The participants who consider it as beneficial also argue that academic inbreeding practice develops their teaching capacities. They may find a chance to conduct their classes under the supervision of their advisors. This result is also supported by other studies. In this context, Harto, and Veloso (2010), Horta, Sato and Yonozewa (2011), Musselin (2004) and Pan (1993) indicate that insider faculty members become better teachers comparing to those coming from other universities. Another reason of benefit of academic inbreeding found in this study is time, energy, and finance. It is reported that the university's short-term recruitment of its graduates shortens the process of seeking candidates, reduces various costs, and removes the risk of election of a candidate who may be a less well-known and false choice from the outside. Through this employment mechanism, universities are able to avoid the risks of employing unknown academic staff and maintain their institutional culture and academic prestige. In this regard, Burris (2004) and Hagstrom (1971) put forward the idea that the more respected universities have higher rates of taking their own graduates. Furthermore, according to Pan (1993), geographical features of universities, or obstacles can limit the potential candidates for universities. Thus, financially and geographically disadvantaged universities can stand out as a suitable option to employ their own graduates. Additionally, outsiders can provide diversity to departments despite having difficulty in terms of adaptation. 
On the other hand, most academicians note that academic inbreeding has negative consequences and therefore, it poses a lot of risks on universities (Macfarlane \& Jefferson, 2021; de la Torre, Perez-Esparrels, \& Romero-Madrid, 2021; Horta, Meoli, \& Santos, 2021; Tavares, Sin, \&Lanca, 2019). In this context, firstly, the participants of this sample consider that academic inbreeding blunts scientific creativity, lowers scientific production, diminishes knowledge sharing, and reduces the mobility of faculty members. They think that employing academicians from different backgrounds, universities and cultures can provide creativity. By implementing academic inbreeding as an employment practice, the academia may reduce its scientific knowledge production, because insider faculty members have a tendency of following similar knowledge production patterns. It is also supported by other study results. In this regard, one outcome can be summarized that insiders who are later employed as faculty members at the university in which they studied, have less scientific production (Banks, 2006; Blanke, Hyle, \& Spring, 2000; Cruz-Castro \& Sanz-Menéndez, 2010; Hargens \& Farr, 1973; Horta, Veloso, \& Grediaga, 2013; İnanç \& Tuncer, 2011; Morichika \& Shibayama, 2015; Yudkevich, 2015). Another negative outcome of becoming academicians at the same university they graduate from is that they can have limited academic experience within a university. The participant academicians add that academic staff cannot experience different academic cultures and meet different scholars from other universities or backgrounds. In Turkey, once academic staff are employed, they may go on working at the same university until they get retired. In fact, when academicians experience a different culture and meet other academicians from other cultures or academic backgrounds, their points of views may change. Academic inbreeding, therefore, can lead the faculty to maintain their own research without allowing diversity. A further risk underlined here is that by implementing such an employment policy, academic freedom may be affected negatively. It is difficult for insider academicians to conduct their researches freely, because there can be an oppression of their superiors. In this case, according to Albatch (2001), Seggie and Gökbel (2014), Metzger (1987), Poch (1993) and UNESCO (2008) academic freedom, which refers to the freedom of academicians to perform all their academic activities without facing any pressure, cannot be fully practiced. Moreover, academic inbreeding is closely related to the rigid working conditions resulting from the absence of a real academic labor market and it can be used as a tool by universities to direct and supervise academic labor markets especially in developing countries. For this reason, academic inbreeding is one of the main problems of higher education all over the world (Eels \& Cleveland, 1935a, 1935b; Musselin, 2004). What is more, academic inbreeding practices limit social capital that faculty members can create by causing them to stay in a certain environment for a long time. This practice may restrict faculty experiences in different environments by forcing them to work at the same university throughout their careers and prevent investment in external qualifications, activities, and productions (Altbach, Yudkevich, \& Rumbley, 2015; Tavares et al., 2015).

According to all results obtained through this research, it can be concluded that even though academic inbreeding has been claimed to have some benefits by few participants in the short term, it is discovered that it may pose many risks on universities as it limits diversity, prevents exchanging knowledge and sharing experience in the long term. This form of employment sometimes leads to harsh discussions at university environment as it may open a road to nepotism as well. As academic inbreeding has become an increasing tradition for universities in Turkey in recent years, this employment practice can sometimes lead to favoritism or nepotism which sounds like a provincial tradition. According to Laufer (2020) when academic inbreeding is still widely practiced within a system, supposed "open calls" for positions are in actuality 'fictitious' as 'no one believes in the possibility of genuinely fair chances for outsiders to succeed'. As a result, academic inbreeding is believed to bring many risks to higher education institutions in the long term. The recommendations reached through this study are presented below:

- Universities should employ academicians from different universities, backgrounds, and experiences. While employing academicians, academic competency should be prioritized.

- It is also important for academic staff to experience different cultures and meet different academicians from other universities and cultures. Therefore, their mobility should be encouraged.

- Favoritism and nepotism should be avoided when employing academic staff.

\section{References}

Alipova, O., \& Lovakov, A. (2018). Academic inbreeding and publication activities of Russian faculty. Tertiary Education and Management, 24(1), 6682. https://doi.org/10.1080/13583883.2017.1395905

Altbach, P. G. (2001). Academic freedom: International realities and challenges. Higher Education, 41(1/2), 205-219. https://doi.org/10.1023/A:1026791518365

Altbach, P. G., Yudkevich, M., \& Rumbley, L. E. (2015). Academic inbreeding: Local challenge, global problem. 
Asia Pasific Education Review, 16, 317-330. https://doi.org/10.1007/s12564-015-9391-8

Bailey, K. D. (1994). Methods of social research. A division of Macmillan. New York: The Free Press.

Balc1, A. (2015). Sosyal bilimlerde araştırma. Ankara: Pegem.

Balyer, A., \& Ömür, Y. E. (2018). Üniversitelerdeki içten beslenmenin akademik özgürlük bağlamında çözümlenmesi. International Journal of Social Science Research, 7(2), 307-325.

Banks, M. G. (2006). An extension of the Hirsch index: Indexing scientific topics and compounds. Scientometrics, 69(1), 161-168. https://doi.org/10.1007/s11192-006-0146-5

Blanke, D. J., \& Hyle, A. E. (2000). Faculty tiering and academic inbreeding: One institution's relationships and realities. Advancing Women in Leadership, 3(1), 1-16.

Blau, P. M. (1994). The organization of academic work. New York: John Wiley \& Sons.

Bogdan, R., \& Biklen, S. (2007). Qualitative research for education: An introduction to theory and practice. Needham Heights, MA: Allyn and Bacon.

Bowen, R. (2005). From the general secretary: Academic freedom undermined: Selfcensorship. Academe, 72.

Burris, V. (2004). The academic caste system: Prestige hierearchies in $\mathrm{PhD}$ exchange networks. American Sociological Review, 69, 239-264. https://doi.org/10.1177/000312240406900205

Cambridge English $\quad$ Dictionary. $\quad$ (2019). $\quad$ Retrieved from https://dictionary.cambridge.org/tr/s\%C3\%B6zl\%C3\%BCk/ingilizce/inbreeding

Creswell, J. W. (2007). Qualitative inquiry ve research design: Choosing among five approaches. Thousand Oaks: Sage.

Crişan, A. N. (2019). Higher education and the challenges of postmodern society. Journal of Educational Science and Psychology, 9(2), 10-16.

Cruz-Castro, L., \& Sanz-Menéndez, L. (2010). Mobility versus job stability: Assessing tenure and productivity outcomes. Research Policy, 39, 27-38. https://doi.org/10.1016/j.respol.2009.11.008

De George, R. T. (Ed.). (1997). Academic freedom and tenure: Ethical issues. Lanham, MD: Rowman and Littlefield.

de la Torre, E. M., Perez-Esparrells, C., \& Romero-Madrid, T. (2021). Academic inbreeding in the Spanish public university system: A review of its institutional and context determinants. Culture and Education, 33(2), 229-258. https://doi.org/10.1080/11356405.2021.1904658

DeMarrais, K. (2004). Qualitative interview studies: Learning through experience. In K. deMarrais \& S. D. Lapan (Eds.), Foundations for research (pp. 51-68). Mahwah: Lawrrence Erlbaum. https://doi.org/10.4324/9781410609373

Denzin, N. K., \& Lincoln, Y. S. (2005). The sage handbook of qualitative research (3rd ed.). Thousand Oaks, CA: Sage.

Eels, W. C., \& Cleveland, A. C. (1935a). Faculty inbreeding. The Journal of Higher Education, 6(5), 261-269. https://doi.org/10.2307/1975545

Eels, W. C., \& Cleveland, A. C. (1935b). The effects of inbreeding. The Journal of Higher Education, 6, 323-328. https://doi.org/10.2307/1975595

Eisenberg, T., \& Wells, M. T. (2000). Inbreeding in law school hiring: Assessing the performance of faculty hired from within. The Journal of Legal Studies, 29(1), 369-388. https://doi.org/10.1086/468077

Glaser, B. G. (1992). Basics of grounded theory analysis. Mill Valley, California: Sociology Press.

Göktürk, D., \& Yıldırım-Taştı, O. (2020). The role of academic inbreeding in building institutional and research habitus: A case study from Turkey. Higher Education Policy, 1-21. https://doi.org/10.1057/s41307-020-00201-1

Gorelova, O., \& Lovakov, A. (2016). Academic inbreeding and research productivity of Russian faculty members. Tertiary Education and Management, 22(2), 149-170. https://doi.org/10.1080/13583883.2016.1177583

Hagstrom, W. O. (1971). Inputs, outputs and the prestige of university science departments. Sociology of Education, 44(4), 375-397. https://doi.org/10.2307/2112029 
Hargens, L. L., \& Farr, G. M. (1973). An examination of recent hypothesis about institutional inbreeding. American Journal of Sociology, 78(6), 1381-1402. https://doi.org/10.1086/225470

Heinze, T., Shapira, P., Rogers, J. D., \& Senker, J. M. (2009). Organizational and institutional influences on creativity in scientific research. Research Policy, 38, 610-623. https://doi.org/10.1016/j.respol.2009.01.014

Horta, H. (2013). Deepening our understanding of academic inbreeding effects on research information exchange and scientific output: new insights for academic based research. Higher Education, 65, 87-510. https://doi.org/10.1007/s10734-012-9559-7

Horta, H., Meoli, M., \& Santos, J. M. (2021). Academic inbreeding and choice of strategic research approaches. Higher Education Quarterly, 1-26. https://doi.org/10.1111/hequ.12328

Horta, H., Sato, M., \& Yonezawa, A. (2011). Academic inbreeding: Exploring its characteristics and rationale in Japanese universities using a qualitative perspective. Asia Pacific Education Review, 12, 35-44. https://doi.org/10.1007/s12564-010-9126-9

Horta, H., Veloso, F. M., \& Grediaga, R. (2010). Navel gazing: Academic inbreeding and scientific productivity. Management Science, 56(3), 414-429. https://doi.org/10.1287/mnsc.1090.1109

Horta, H., \& Yudkevich, M. (2015). The role of academic inbreeding in developing higher education systems: challenges and possible solutions. Technological Forecasting ve Social Change, 1-10. https://doi.org/10.1016/j.techfore.2015.06.039

İnanç, Ö., \& Tuncer, O. (2011). The effects of academic inbreeding on scientific effectiveness. Scientometrics, 88, 885-898. https://doi.org/10.1007/s11192-011-0415-9

Kerkhof, M. (2006). The repertory grid technique. (RGT), integrated assessment. Retrieved August 3, 2018, from http://www.ivm.vu.nl/en/Images/PT4_tcm234-161509.pdf

Kozikoğlu, İ. (2016). Academic Inbreeding: A Conceptual Analysis. International Journal of Social Science, 49, 349-357. https://doi.org/10.9761/JASSS3660.

Kümbetoğlu, B. (2005). Sosyolojide ve antropolojide niteliksel yöntem ve araştırma. İstanbul: Bağlam.

Laufer, M. (2020). Crossing academic borders: exploring the role of social capital in academic hiring. Comparative Education, 56(3), 1-19. https://doi.org/10.1080/03050068.2020.1782603

Liu, S. (2005, May). Defending against business crises with the help of intelligent agent based early warning solutions. Paper presented at the Seventh International Conference on Enterprise Information Systems, Miami, FL. Retrieved from http://www.iceis.org/iceis2005/abstracts_2005.htm

Macfarlane, B., \& Jefferson, A. E. (2021). The closed academy? Guild power and academic social class. Higher Education Quarterly, 1-12. https://doi.org/10.1111/hequ.12305

Machacek, V., Srholec, M., Ferreira, M. R., Robinson-Garcia, \& Costas, R. (2021). Researchers' institutional mobility: Bibliometric evidence on academic inbreeding and internationalization. Science and Public Policy. https://doi.org/10.1093/scipol/scab064

Marshall, C., \& Rossman, G. B. (2006). Designing qualitative research (4 th ed.). Thousand Oaks, CA: Sage.

Marvasti, A. (2004). Qualitative research in sociology. https://doi.org/10.4135/9781849209700

Massengale, J. D., \& Sage, G. H. (1982). Departmental prestige and career mobility patterns of college physical educators. Research Quarterly for Exercise and Sport, 53(4), 305-312. https://doi.org/10.1080/02701367.1982.10605253

Mayring, P. (2000). Qualitative content analysis. Forum: Online Journal Qualitative Social Research, 1(2), $1-10$.

Metzger, W. P. (1987). Profession and constitution: Two definitions of academic freedom in America. Texas Law Review, 66, 1265-1322.

Miles, M. B., \& Huberman, M. A. (1994). Qualitative data analysis: A sourcebook of new methods. Beverly Hills: Sage.

Mishra, V., \& Smyth, R. (2012). Academic inbreeding and research productivity in Australian law schools, Department of Economics Discussion Paper, 46(12), 1-56.

Morichika, N., \& Shibayama, S. (2015). Impact of inbreeding on scientific productivity: A case study of a Japanese university department. Research Evaluation, 24, 146-157. https://doi.org/10.1093/reseval/rvv002 
Musselin, C. (2004). Towards a European academic labour market? Some lessons drawn from empirical studies on academic mobility. Higher Education, 48, 55-78. https://doi.org/10.1023/B:HIGH.0000033770.24848.41

Padilla, L. E. (2008). How has Mexican faculty been trained? A national perspective and a case study. Higher Education, 56, 167-183. https://doi.org/10.1007/s10734-007-9096-y

Pan, S. (1993). A study of faculty inbreeding at eleven land-grant universities. Unpublished PhD Thesis. Iowa State University, Iowa, Canada.

Patton, M. (2002). Qualitative research and evaluation methods. Thousand Oaks: Sage.

Poch, R. K. (1993). Academic freedom in American higher education: Rights, responsibilities, and limitations. Retrieved from https://eric.ed.gov/?id=ED366263

Resmi, G. (2008). Öğretim üyesi dışındaki öğretim elemanı kadrolarına naklen veya açıktan yapılacak atamalarda uygulanacak merkezi sinav ile giriş sinavlarına ilişkin usul ve esaslar hakkında yönetmelik. Retrieved from https://www.resmigazete.gov.tr/eskiler/2016/03/20160314-1.htm

Seeber, M., \& Mampaey, J. (2021). How do university systems' features affect academic inbreeding? Career rules and language requirements in France, Germany, Italy and Spain. Higher Education Quarterly, 1-16. https://doi.org/10.1111/hequ.12302

Seggie, N., \& Gökbel, V. (2014). Geçmişten günümüze Türkiye'de akademik özgürlük, SETA, Siyaset ve Ekonomi ve Toplum Araştırmaları Vakfi. İstanbul: Turkuvaz Matbaacılık Yayıncılık A.Ş.

Summak, M. S. (1998). Academic human rights and freedoms in Turkey. The Educational Forum, 62(1), 32-39. https://doi.org/10.1080/00131729708982678

Tavares, O., Cardoso, S., Carvalho, T., Sousa, S. B., \& Santiago, R. (2015). Academic inbreeding in the Portuguese academia. Higher Education, 69, 991-1006. https://doi.org/10.1007/s10734-014-9818-x

Tavares, O., Lança, V., \& Amaral, A. (2015). Academic inbreeding in Portuguese islands: Does insularity play a role? Paper presented in "Governance and Leadership", EAIR 37th Annual Forum. https://doi.org/10.1057/s41307-016-0029-1

Tavares, O., Sin, C., \& Lança, V. (2019). Inbreeding and research productivity among sociology PhD holders in Portugal. Minerva, 57, 373-390. https://doi.org/10.1007/s11024-019-09378-1

UNESCO. (2008). 1997 Recommendation concerning the status of higher education teaching personnel. Paris, France: United Nations Educational, Scientific and Cultural Organization.

Washington: George Washington University Punch, K. F. (2005). Sosyal araştırmalara giriş̧ (Nitel ve Nicel Yaklaşımlar) (Çev. D. Bayrak, H. B. Arslan ve Z. Akyüz). Ankara: Siyasal.

Yudkevich, M. M. (2015). The Russian academic profession and the creation of advanced universities. Russian Education ve Society, 57(6), 519-530. https://doi.org/10.1080/10609393.2015.1096141

\section{Copyrights}

Copyright for this article is retained by the author, with first publication rights granted to the journal.

This is an open-access article distributed under the terms and conditions of the Creative Commons Attribution license (http://creativecommons.org/licenses/by/4.0/). 